ARTICLE

https://doi.org/10.1038/s41467-020-16213-9

\title{
Structural basis for impairment of DNA methylation by the DNMT3A R882H mutation
}

Hiwot Anteneh ${ }^{1}$, Jian Fang ${ }^{1} \&$ Jikui Song (iD ${ }^{1 \times}$

DNA methyltransferase DNMT3A is essential for establishment of mammalian DNA methylation during development. The R882H DNMT3A is a hotspot mutation in acute myeloid leukemia (AML) causing aberrant DNA methylation. However, how this mutation affects the structure and function of DNMT3A remains unclear. Here we report structural characterization of wild-type and R882H-mutated DNMT3A in complex with DNA substrates with different sequence contexts. A loop from the target recognition domain (TRD loop) recognizes the $\mathrm{CpG}$ dinucleotides in a +1 flanking site-dependent manner. The $\mathrm{R} 882 \mathrm{H}$ mutation reduces the DNA binding at the homodimeric interface, as well as the molecular link between the homodimeric interface and TRD loop, leading to enhanced dynamics of TRD loop. Consistently, in vitro methylation analyses indicate that the $\mathrm{R} 882 \mathrm{H}$ mutation compromises the enzymatic activity, $\mathrm{CpG}$ specificity and flanking sequence preference of DNMT3A. Together, this study uncovers multiple defects of DNMT3A caused by the R882H mutation in AML.

\footnotetext{
${ }^{1}$ Department of Biochemistry, University of California, Riverside, CA 92521, USA. ${ }^{凶}$ email: jikui.song@ucr.edu
} 
$\mathrm{D}$ NA methylation is an important epigenetic mechanism that critically impacts cell proliferation and lineage commitment during development ${ }^{1,2}$. In mammals, DNA methylation mainly occurs at the C-5 position of cytosines within CpG dinucleotides, accounting for $70-80 \%$ of all $\mathrm{CpG}$ sites in the genome $^{3}$. Mammalian DNA methylation is established by de novo DNA methyltransferases DNMT3A and DNMT3B ${ }^{4}$, and subsequently subjected to maintenance by DNA methyltransferase DNMT1 in a replication-dependent manner ${ }^{5}$. DNMT3Amediated DNA methylation is further regulated by DNMT3-like protein (DNMT3L) during gametogenesis and embryogenesis ${ }^{6-8}$. Dysregulation of DNA methylation is associated with various human diseases 9 , such as cancers ${ }^{10,11}$. Among these, mutation of DNMT3A has been identified in $~ 25 \%$ acute myeloid leukemia (AML) patients ${ }^{12-15}$, which gives rise to aberrant DNA methylation patterns and increased cell proliferation ${ }^{16-18}$, and correlates with poor clinical outcome ${ }^{13}$.

DNMT3A R882H mutation represents the most frequent DNMT3A missense mutation in AML ${ }^{13}$. Previous studies have demonstrated that this mutation leads to CpG DNA hypomethylation and altered gene regulation in hematopoietic or embryonic stem (ES) cells $16,17,19$. Consistently, it has been reported that the $\mathrm{R} 882 \mathrm{H}$ mutation impairs the enzymatic activity of DNMT3A ${ }^{16,17,20-24}$, and destabilizes its tetrameric form in vitro and in cells $s^{17,22,23}$. Furthermore, recent studies have suggested that the $\mathrm{R} 882 \mathrm{H}$ mutation may affect the relative enzymatic preference of DNMT3A toward different CpGflanking sequences: in comparison with wild-type DNMT3A, the $\mathrm{R} 882 \mathrm{H}$ mutant shows stronger preference for the $\mathrm{CG}(\mathrm{G} / \mathrm{A})$ motif over the $C G(T / C)$ motif as substrate ${ }^{25}$, which correlates with the aberrant DNA methylation and gene expression in AML, suggesting an off-targeting effect of the DNMT3A R882H mutation that may contribute to AML pathogenesis ${ }^{21}$.

The structures of DNMT3A in complex with DNMT3L have been reported, revealing that DNMT3A dimerizes through two alternative interfaces: a DNMT3A-DNMT3A homodimeric interface (a.k.a. $\mathrm{RD}$ interface) mediated by polar interactions and a DNMT3A-DNMT3L interface (a.k.a. FF interface) mediated by hydrophobic contacts $24,26,27$. Our recent study on the complex between DNMT3A-DNMT3L and CpG DNA further demonstrated that the DNMT3A-DNA interaction is mediated by three distinct regions: a loop from the target recognition domain (TRD loop), a loop from the catalytic core (catalytic loop) and the $\mathrm{RD}$ interface of DNMT3A ${ }^{24}$. Notably, residue R836 from the TRD loop forms a hydrogen bond with the $\mathrm{CpG}$ site, which contributes to the CpG specificity of DNMT3A ${ }^{24}$. Structural analysis of the DNMT3A-DNMT3L-DNA complex also confirmed a role of R882, located on the RD interface, in DNA binding ${ }^{24}$. In addition, an intramolecular hydrogen bond is formed between residues R882 and S837, establishing a link between the TRD loop and RD interface.

To gain further insights into the context-dependent DNA methylation by DNMT3A and the mutational effect of R882H, we determined the crystal structure of wild-type DNMT3A $\left(\right.$ DNMT3A $\left.{ }^{\mathrm{WT}}\right)$-DNMT3L tetramer in complex with a CGA motif-containing DNA, as well as R882H-mutated DNMT3A (DNMT3A $\mathrm{A}^{\mathrm{R} 82 \mathrm{H}}$ )-DNMT3L tetramer in complex with CGAand CGT-containing DNAs. Our study reveals that the TRD loop in the DNMT3A ${ }^{\text {WT }}$-DNMT3L-CGA DNA complex recognizes the $\mathrm{CpG}$ site in a different mechanism than that in the previously reported DNMT3A ${ }^{\text {WT }}$-DNMT3L-CGT DNA complex ${ }^{24}$, therefore uncovering the inherent conformational dynamics of the TRD loop. The R882H mutation not only impairs the protein-DNA contact at the $\mathrm{RD}$ interface, but also perturbs the molecular interaction between the RD interface and the TRD loop, leading to altered conformational flexibility of the TRD loop and its context-dependent DNA contact. Consistently, in vitro methylation analyses indicate that the $\mathrm{R} 882 \mathrm{H}$ mutation impairs both the CpG methylation efficiency and specificity of DNMT3A. Together, these studies uncover a multifaceted defect of DNMT3A caused by the R882H mutation.

\section{Results}

Structure of the DNMT3A ${ }^{W T}$-DNMT3L-CGA DNA complex. Our previous study delineated the interaction between DNMT3A $\mathrm{AT}^{\mathrm{WT}}$-DNMT3L and DNA containing two CGT motifs ${ }^{24}$. To further investigate how the sequence context of DNA substrates affects DNMT3A-mediated DNA methylation, we set out to determine the crystal structure of DNMT3A ${ }^{\mathrm{WT}}$-DNMT3L tetramer in complex with a CGA-containing DNA duplex. In essence, we generated the DNMT3A $\mathrm{WT}^{\mathrm{WT}} \mathrm{DNMT} 3 \mathrm{~L}$ tetramer using the MTase domain of DNMT3A ${ }^{\mathrm{WT}}$ and the C-terminal domain of DNMT3L (Fig. 1a). The DNA substrate was prepared by annealing of a self-complimentary 25-mer DNA in which the cytosine within the CGA motif is replaced by a zebularine ( $\mathrm{Z})$, a cytosine analogue ${ }^{28}$. The resulting DNA duplex harbors two separate $(\mathrm{ZpGpA}) \cdot(\mathrm{TpCpG})$ sites, mimic of two (CpGpA) • (TpCpG) sites (denoted herein as CGA DNA) (Fig. 1b). The crystal structure of the DNMT3A ${ }^{\mathrm{WT}}$-DNMT3L-CGA DNA (DNMT3A WT_CGA) complex, bound to cofactor byproduct $S$-Adenosyl-L-homocysteine (SAH), was solved by Molecular Replacement using the reported crystal structure of DNMT3A $\mathrm{WT}_{-}$ DNMT3L-CGT DNA (DNMT3AWT_CGT) complex (PDB $5 Y X 2)^{24}$ as template. The resulting electron density map permitted us to model the entire DNMT3A and DNA molecules. The majority of DNMT3L was also modeled, except for a few loop segments (residues 209-217, 314-317, 354-357 and 380-386). The structure of the DNMT3A ${ }^{\mathrm{WT}}$-CGA complex was refined to $2.40 \AA$ resolution (Fig. 1c and Supplementary Table 1).

The structure of the DNMT3A ${ }^{\mathrm{WT}}$-CGA complex resembles that of the DNMT3A ${ }^{\mathrm{WT}}-\mathrm{CGT}$ complex (Fig. 1c) ${ }^{24}$, with the zebularines flipped into the active sites of the DNMT3A WT molecules, stabilized via covalent linkage with catalytic cysteine C710 of DNMT3A ${ }^{\mathrm{WT}}$ and hydrogen-bonding interactions with other catalytic residues (Fig. 1c). The protein-DNA interaction is mainly mediated by the TRD loop (residues 831-848), catalytic loop (residues 707-721) and a segment at the RD interface (residues 881-887) of DNMT3A ${ }^{\text {WT }}$ (Fig. 1c and Supplementary Fig. $1 \mathrm{a}, \mathrm{b})$. The TRD loop extends into the DNA major groove, with residues T834 and N838 engaging water-mediated and direct hydrogen-bonding interactions with the N7 and O6 atoms of G6, respectively (Fig. 1d). Meanwhile, residue T835 forms a hydrogen bond with the backbone phosphate of G6, and the side chain of residue $\mathrm{R} 836$ approaches the $+1-+3$ flanking nucleotides (A7T8 and G9') of the CpG site, donating the guanidinium group for hydrogen-bonding interactions with A7 and T8 of the target strand and G9' of the non-target strand (Fig. 1d). Toward the minor groove, the catalytic loop interacts with the unpaired $\mathrm{CpG}$ guanine $\left(\mathrm{G}^{\prime} / \mathrm{G} 20\right)$ and surrounding DNA backbone through hydrogen-bonding interactions, as well as stacking contacts between residues V716 and P718 and ZpG guanine (G6/G19') (Fig. 1e). In addition, residues S881, R882, L883, and R887 at the RD interface interact with the DNA backbone (T14-G16 and G9'$\mathrm{T} 11^{\prime}$ ) through hydrogen bonding, electrostatic or van der Waals contacts (Fig. 1f). Together, these interactions form threepronged contacts between DNMT3A dimers and DNA, resulting in a buried surface area of $\sim 2800 \AA^{2}$. On the other hand, DNMT3L is not involved in any contact with DNA, as observed previously ${ }^{24}$. 
a

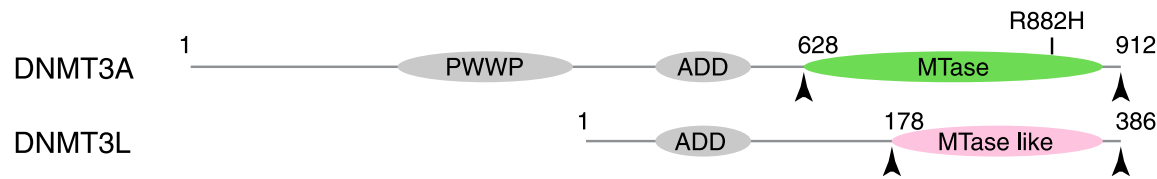

b

CGA $5^{\prime}-$ - $C_{1} A_{2} T_{3} G_{4} Z_{5} G_{6} A_{7} T_{8} C_{9} T_{10} A_{11} A_{12} T_{13} T_{14} A_{15} G_{16} A_{17} T_{18} C_{19} G_{20} C_{21} A_{22} T_{23} G_{24} G_{25}-3^{\prime}$

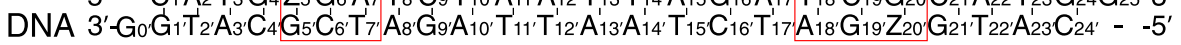

C

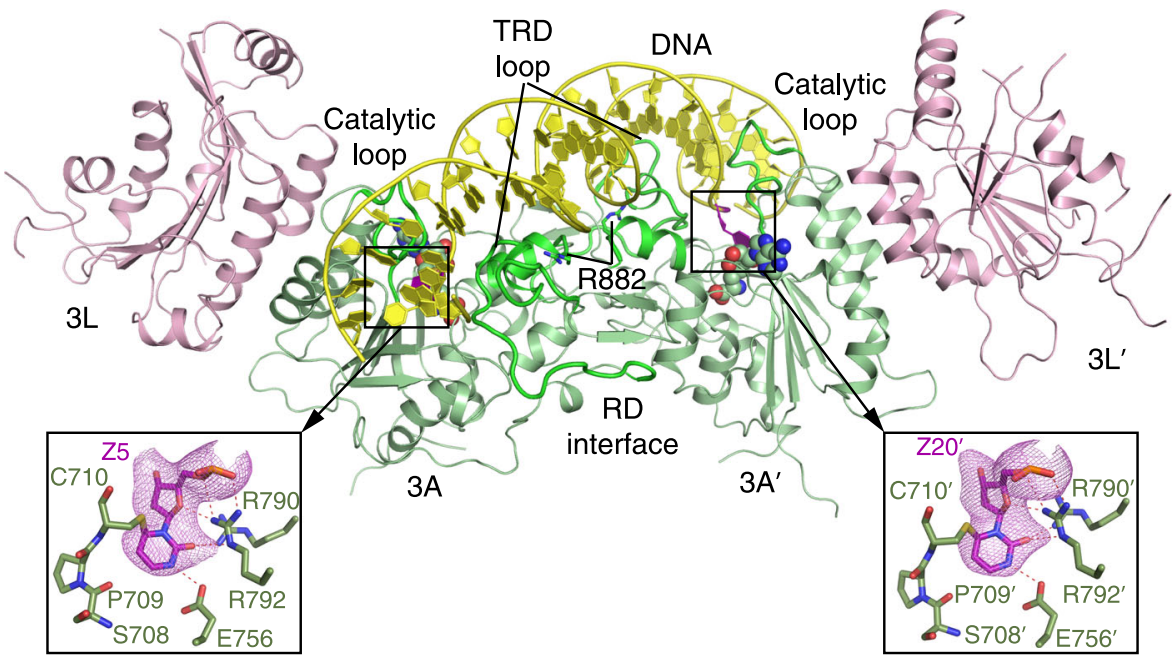

d

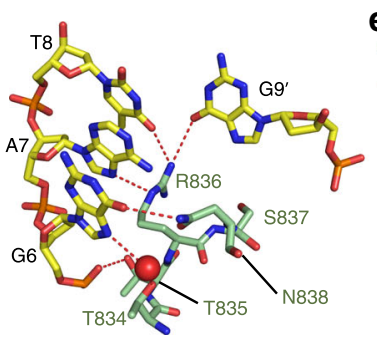

e

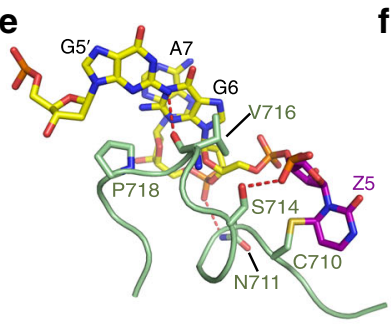

f

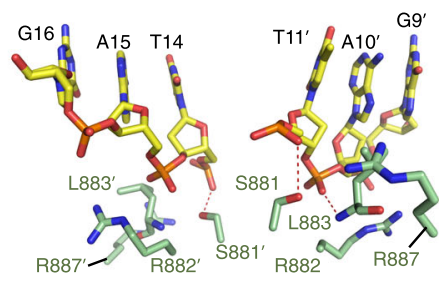

Fig. 1 Structure of the DNMT3AWT-DNMT3L tetramer in complex with CGA DNA. a Domain architecture of DNMT3A and DNMT3L with the C-terminal domains marked with arrowheads. The site for R882H mutation is marked. $\mathbf{b}$ DNA sequence (CGA) used for the structural study. Z, zebularine. $\mathbf{c}$ Ribbon representations of DNMT3AWT-DNMT3L bound to CGA DNA and SAH, with residue R882 marked. The zebularines anchored at the two active sites are shown in expanded views, with hydrogen-bonding interactions depicted as dashed lines and Fo-Fc omit map (violet) contoured at 2.0 sigma level. The SAH molecules are shown in sphere representation. $\mathbf{d}$-f Close-up views of the DNA interactions of the TRD loop (d), catalytic loop (e) and RD interface (f) of DNMT3AWT.

Structural comparison of DNMT3 $\mathrm{A}^{\mathrm{WT}}$-CGA and DNMT3A ${ }^{\mathrm{WT}}$ CGT. Structural comparison of DNMT3A ${ }^{\mathrm{WT}}$-CGA with DNMT3A ${ }^{\text {WT }}$-CGT reveals high structural similarity over the entire complex, with root-mean-square deviation (RMSD) of $0.42 \AA$ over 821 aligned $\mathrm{C} a$ atoms (Fig. 2a). Nevertheless, the DNMT3A ${ }^{\mathrm{WT}_{-}}$ CGA complex differs considerably from the DNMT3A ${ }^{\text {WT }}$-CGT complex in two regions: the TRD loop and the RD interface (Fig. 2b,c). In the DNMT3A ${ }^{\mathrm{WT}}-\mathrm{CGT}$ complex, the side chain of residue R836 on the TRD loop forms a base-specific hydrogen bond with G6, while the neighboring N838 forms a hydrogen bond with the DNA backbone (Supplementary Fig. 1c); in contrast, in the DNMT3A ${ }^{\text {WT }}$-CGA complex, the side chain of R836 flips away from G6 to interact with the $+1-+3$ flanking nucleotides through hydrogen-bonding interactions; meanwhile, the side chain of N838 turns to occupy the space vacated by the flipped R836, thereby engaging a base-specific hydrogen-bonding interaction with G6 (Fig. $2 \mathrm{~b}$ and Supplementary Fig. 1d). Such a conformational rearrangement in the TRD loop also perturbs the interaction between the $\mathrm{RD}$ interface and the TRD loop (Fig. $2 \mathrm{~b}$ ): the hydrogen bond formed between the side chain of R882 and the backbone carbonyl of 5837 in the DNMT3A ${ }^{\text {WT }}$-CGT complex becomes disrupted in the DNMT3A ${ }^{\mathrm{WT}}$-CGA complex (Fig. 2b). Given that our previous study indicated that the TRD loop undergoes a disorder-to-order transition upon substrate binding, with the substrate-bound form partially stabilized by the interaction between the TRD loop and $\mathrm{RD}$ interface ${ }^{24}$, we surmised that loss of the hydrogen bond between 5837 and R882 in the DNMT3A ${ }^{\text {WT }}$-CGA complex would presumably lead to enhanced flexibility of the TRD loop. Indeed, Bfactor analysis of the two DNMT3A ${ }^{\text {WT }}$-DNA complexes indicates that whereas residues R836-N838 in the DNMT3A ${ }^{\text {WT }}$-CGT complex are associated with an averaged B-factor $\left(66.5 \AA^{2}\right)$, which is comparable with the overall averaged B-factor of DNMT3A $\left(62.5 \AA^{2}\right)$, the same region in the DNMT3A $\mathrm{A}^{\mathrm{WT}}$-CGA complex is associated with an averaged B-factor $\left(87.7 \AA^{2}\right)$ significantly higher than the overall averaged B-factor $\left(70.9 \AA^{2}\right)$, supporting the enhanced flexibility of the TRD loop in the DNMT3A ${ }^{\mathrm{WT}_{-}}$-CGA complex.

In line with the perturbation of the interaction between the TRD loop and $\mathrm{RD}$ interface, structural comparison of the DNMT3A ${ }^{\mathrm{WT}}$-CGA and DNMT3A ${ }^{\mathrm{WT}}$-CGT complexes also reveals a subtle conformational change in the $\mathrm{RD}$ interface (Fig. 2c). In the DNMT3A ${ }^{\mathrm{WT}}$-CGT complex, residues S881, $\mathrm{R} 882$, L883, and R887 on the RD interface all engage side-chain hydrogen-bonding or van der Waals interactions with DNA 
a

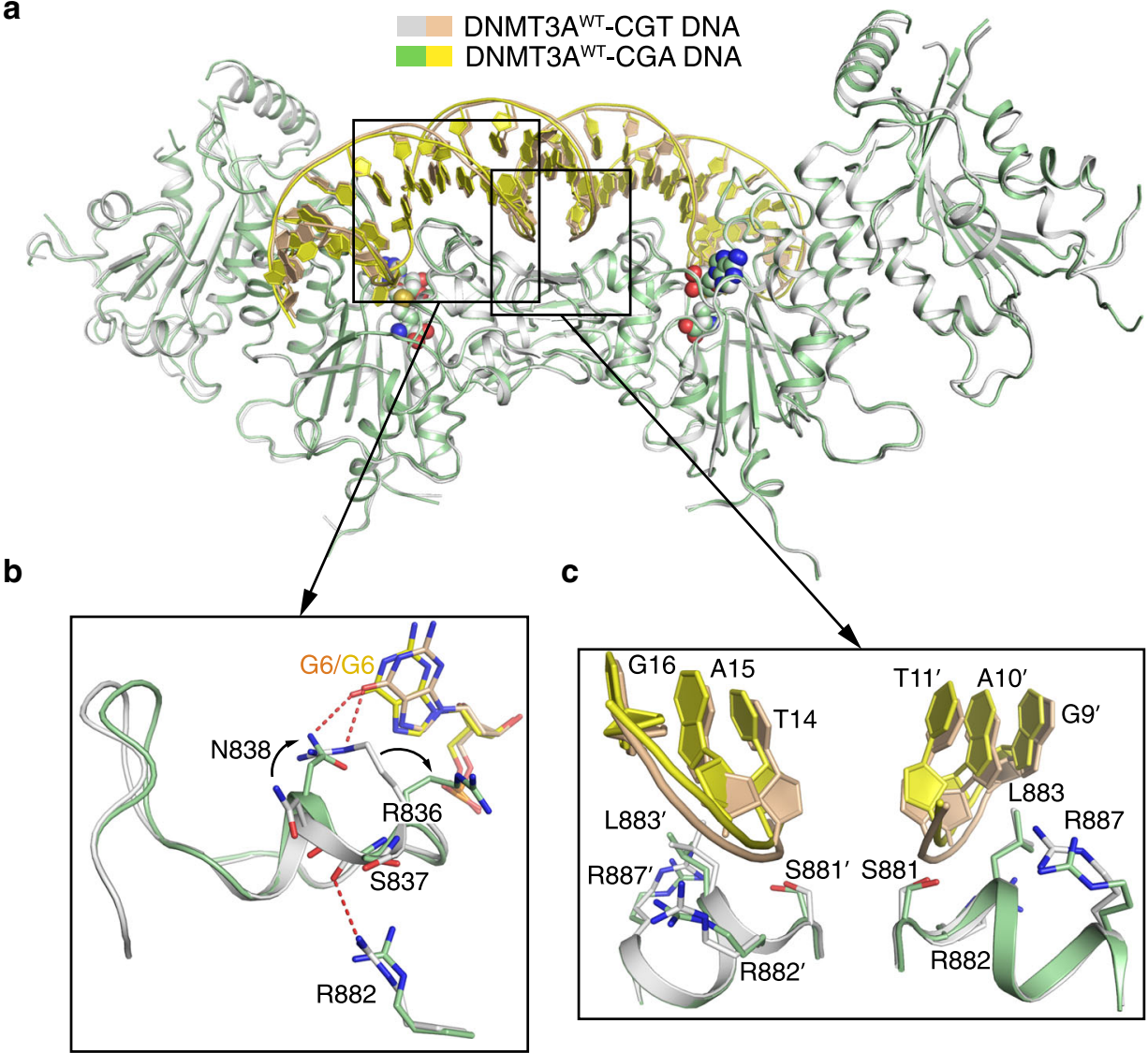

d

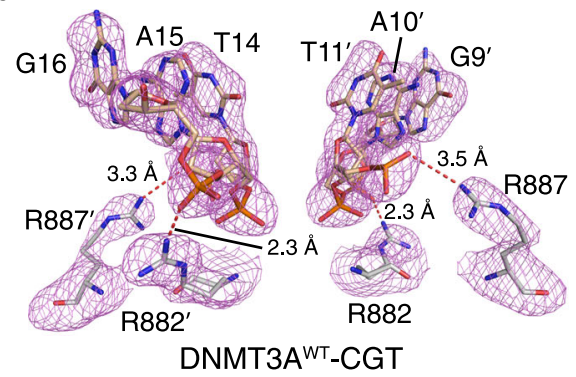

e

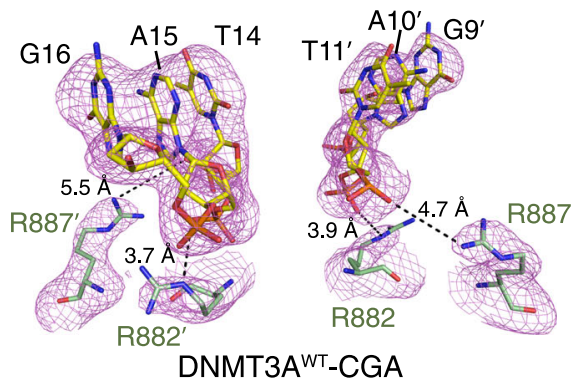

Fig. 2 Structural comparison of the DNMT3AWT-CGA and DNMT3AWT_CGT complexes. a Structural superposition of the DNMT3AWT-CGA and DNMT3AWT-CGT (PDB 5YX2) complexes. b Structural comparison of the TRD loop and its interactions with CpG guanine (G6) and R882 in the DNMT3AWT-CGA and DNMT3AWT-CGT complexes. The conformational rearrangements of the TRD residues between the two complexes are indicated by arrows. c Structural comparison of the RD interface between the DNMT3AWT-CGA and DNMT3AWT-CGT complexes. d,e Close-up views of the R882and R887-engaged DNA interactions in the DNMT3AWT-CGT (PDB 5YX2) (d) and DNMT3AWT-CGA (e) complexes, with the Fo-Fc omit map (violet) contoured at 2.0 sigma level. The distances for hydrogen-bonding and electrostatic interactions are measured and indicated by dashed lines, colored in red and black, respectively.

backbone (Fig. 2c, d), resulting in a buried surface area of $423 \AA^{2}$. By contrast, in the DNMT3A ${ }^{\text {WT }}$-CGA complex, although residues S881 and L883 retain the same fashion of DNA interactions, the other two residues, R882 and R887, are no longer within a distance for hydrogen bond formation with the DNA backbone (Fig. 2c, e), leading to a reduced buried surface area $\left(289 \AA^{2}\right)$ in this region.

Together, these observations suggest that the CpG sites with different flanking sequences may result in different CpG-recognition modes of the TRD loop, as well as perturbation of the interaction between the TRD loop and the RD interface.
Structure of the DNMT3A ${ }^{\text {R882H}}-$ CGA DNA complex. To understand how the R882H mutation of DNMT3A affects its structure and function, we determined the crystal structure of the complex between the DNMT3A $\mathrm{A}^{\mathrm{R} 82 \mathrm{H}}$-DNMT3L tetramer and CGA DNA (DNMT3A ${ }^{\mathrm{R} 882 \mathrm{H}}-\mathrm{CGA}$ ), containing the same sequence as that for the DNMT3A ${ }^{\mathrm{WT}}$-CGA complex, and SAH at $2.5 \AA$ resolution (Fig. 3a and Supplementary Table 1). Structural alignment of the entire DNMT3A $\mathrm{R}^{\mathrm{R} 82 \mathrm{H}_{-}} \mathrm{CGA}$ com-

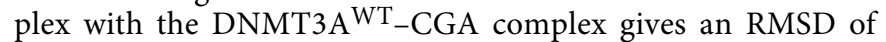
$0.29 \AA$ over 875 aligned $\mathrm{C} \alpha$ atoms, suggesting that the R882H mutation does not alter the structural integrity of the DNMT3A-DNMT3L tetramer (Fig. 3a). The most notable 
a

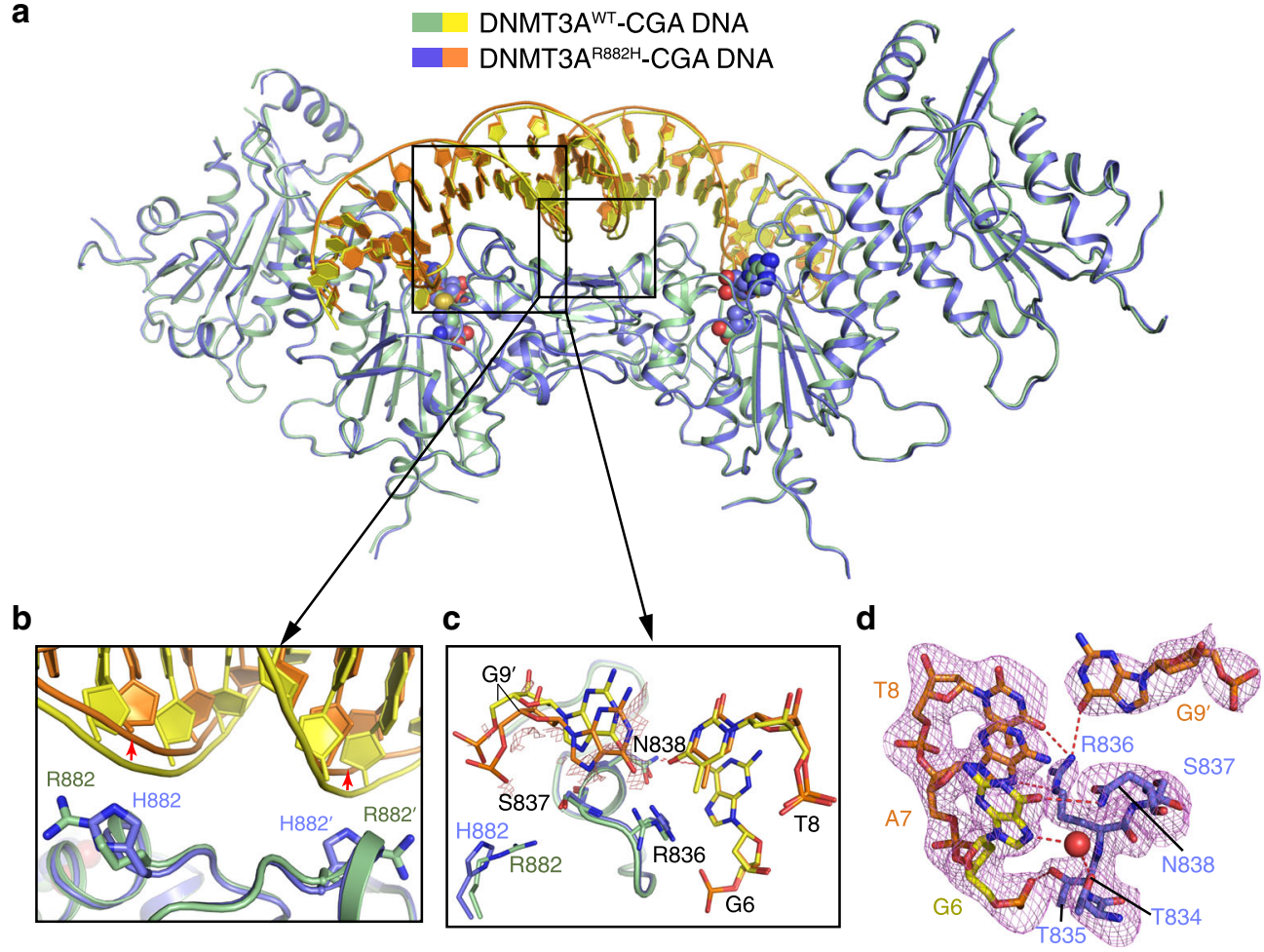

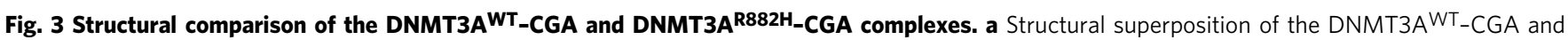
DNMT3A ${ }^{R 882 H}-C G A$ complexes. b Structural comparison of the RD interface between the DNMT3AWT-CGA and DNMT3AR882H_CGA complexes. c Structural comparison of the TRD loop and its interactions with CpG guanine (G6) and R882 in the DNMT3AWT-CGA and DNMT3AR882H-CGA complexes. The hydrogen-bonding interactions are indicated by dashed lines. The conformational difference of G9' is validated by the Fo-Fo difference map (salmon) between the two complexes, contoured at 1.0 sigma level. d Close-up views of the DNA interactions of the TRD loop in the DNMT3A R882H_CGA complex, with the Fo-Fc omit map (violet) contoured at 2.0 sigma level. The water molecule is shown as a red sphere.

structural difference between the DNMT3A $\mathrm{AT}^{\mathrm{WT}} \mathrm{CGA}$ and

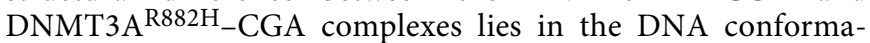
tion: In comparison with the DNMT3A ${ }^{\mathrm{WT}}$-CGA complex, the central segment of the DNMT3A $\mathrm{R}^{\mathrm{R} 82 \mathrm{H}}$-bound DNA molecule bends away by $\sim 2 \AA$ from the RD interface in the DNMT3A ${ }^{\text {R882H }}$-CGA complex (Fig. $3 b$ and Supplementary Fig. 2a). The protein-DNA contact at the RD interface of DNMT $3 \mathrm{~A}^{\mathrm{R} 882 \mathrm{H}}$ in the CGA DNA complex is mainly mediated by residues S881, H882, and L883, which form hydrogen bonds and/or van der Waals contacts with the DNA backbone (Supplementary Fig. $2 \mathrm{~b}, \mathrm{c})$. The fact that the DNMT3A $\mathrm{R}^{\mathrm{R} 82 \mathrm{H}}-\mathrm{CGA}$ complex was crystalized under acidic condition $(\mathrm{pH} 4.2$; see Methods) likely contributed to the H882-mediated hydrogenbonding interaction. In addition, the side chain of R887 is poised for electrostatic interaction with the backbone phosphate of A15/A10' (Supplementary Fig. 2c). Together, these interactions lead to a buried surface area of $238 \AA^{2}$ in this region, lower than that for the DNMT3A ${ }^{\mathrm{WT}}$-CGA complex, suggesting that the $\mathrm{R} 882 \mathrm{H}$ mutation leads to reduced proteinDNA contact at the RD interface.

The TRD loop in the DNMT3A $\mathrm{R}^{\mathrm{R} 82 \mathrm{H}}$-CGA complex adopts a similar conformation to that in the DNMT3A WT_CGA complex, with residue N838 engaging a base-specific hydrogen-bonding interaction with G6, and R836 forming hydrogen bonds with the +2 (T8) and $+3\left(\mathrm{G}^{\prime}\right.$ ) flanking bases (Fig. 3c, d). Nevertheless, subtle conformational shift was observed for $\mathrm{G}^{\prime}$, likely resulting from the altered DNA curvature (Fig. 3c). In addition, residues T834 and T835 both engage DNA contacts in the same fashion as their counterparts in the DNMT3A ${ }^{\mathrm{WT}}$-CGA complex (Fig. 3c). Furthermore, as with the DNMT3A ${ }^{\mathrm{WT}}$-CGA complex, the hydrogen bond between the side chain of R882 and the backbone carbonyl of S837 is also abrogated in the DNMT3A ${ }^{\mathrm{R} 882 \mathrm{H}}-\mathrm{CGA}$ complex (Fig. 3c). Accordingly, residues R836-N838 are associated with a significantly higher averaged B-factor $\left(80.7 \AA^{2}\right)$ than that averaged for the entire DNMT3 $\mathrm{A}^{\mathrm{R} 882 \mathrm{H}}$ molecule $\left(65.2 \AA^{2}\right)$, indicating the significant conformational dynamics of the TRD loop in the DNMT3A ${ }^{\text {R882H}}-$ CGA complex.

Crystal structure of the DNMT3A $\mathrm{A}^{\mathrm{R} 82 \mathrm{H}}$-CGT DNA complex. Next, to elucidate how the R882H mutation influences the contextdependent DNA methylation by DNMT3A, we characterized the structure of the DNMT3A $\mathrm{A}^{\mathrm{R} 82 \mathrm{H}}$-DNMT3L tetramer in complex

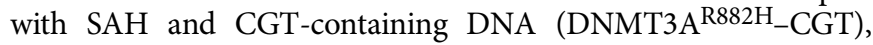
with the same sequence as that previously used for crystalizing the DNMT3AWT_CGT complex ${ }^{24}$ (Supplementary Fig. 3a). The structure of the DNMT3A $\mathrm{R}^{\mathrm{R} 82 \mathrm{H}}$-CGT complex was solved at $2.6 \AA$ resolution (Fig. 4a and Supplementary Table 1), well aligned with that of the DNMT3A ${ }^{\mathrm{WT}}$-CGT complex, with an RMSD of $0.37 \AA$ over 849 aligned $\mathrm{Ca}$ atoms (Fig. 4a).

Structural comparison of the DNMT3A $\mathrm{A}^{\mathrm{R} 882 \mathrm{H}}-\mathrm{CGT}$ and DNMT3A ${ }^{\mathrm{WT}}$-CGT complexes again reveals a difference in the DNA conformation: relative to the DNMT3A ${ }^{\mathrm{WT}}$-bound DNA, the DNMT3A $\mathrm{A}^{\mathrm{R} 882 \mathrm{H}}$-bound DNA moves away from the RD interface by $\sim 3 \AA$, reflective of reduced protein-DNA contact (Fig. $4 \mathrm{a}$ ). Indeed, protein residues on the RD interface engage much reduced protein-DNA contacts in the DNMT3A ${ }^{\mathrm{R} 882 \mathrm{H}}-\mathrm{CGT}$ complex than the corresponding region in the DNMT3A $\mathrm{WT}_{-} \mathrm{CGT}$ complex (Fig. $4 \mathrm{~b}$ and Supplementary Fig. 3b,c). Of particular note, the side chains of residues $\mathrm{H} 882$ and R887 in the DNMT3A ${ }^{\text {R882H_CGT }}$ complex are positioned further away from the DNA backbone than their counterparts in the DNMT3A ${ }^{\mathrm{WT}}$-CGT complex 


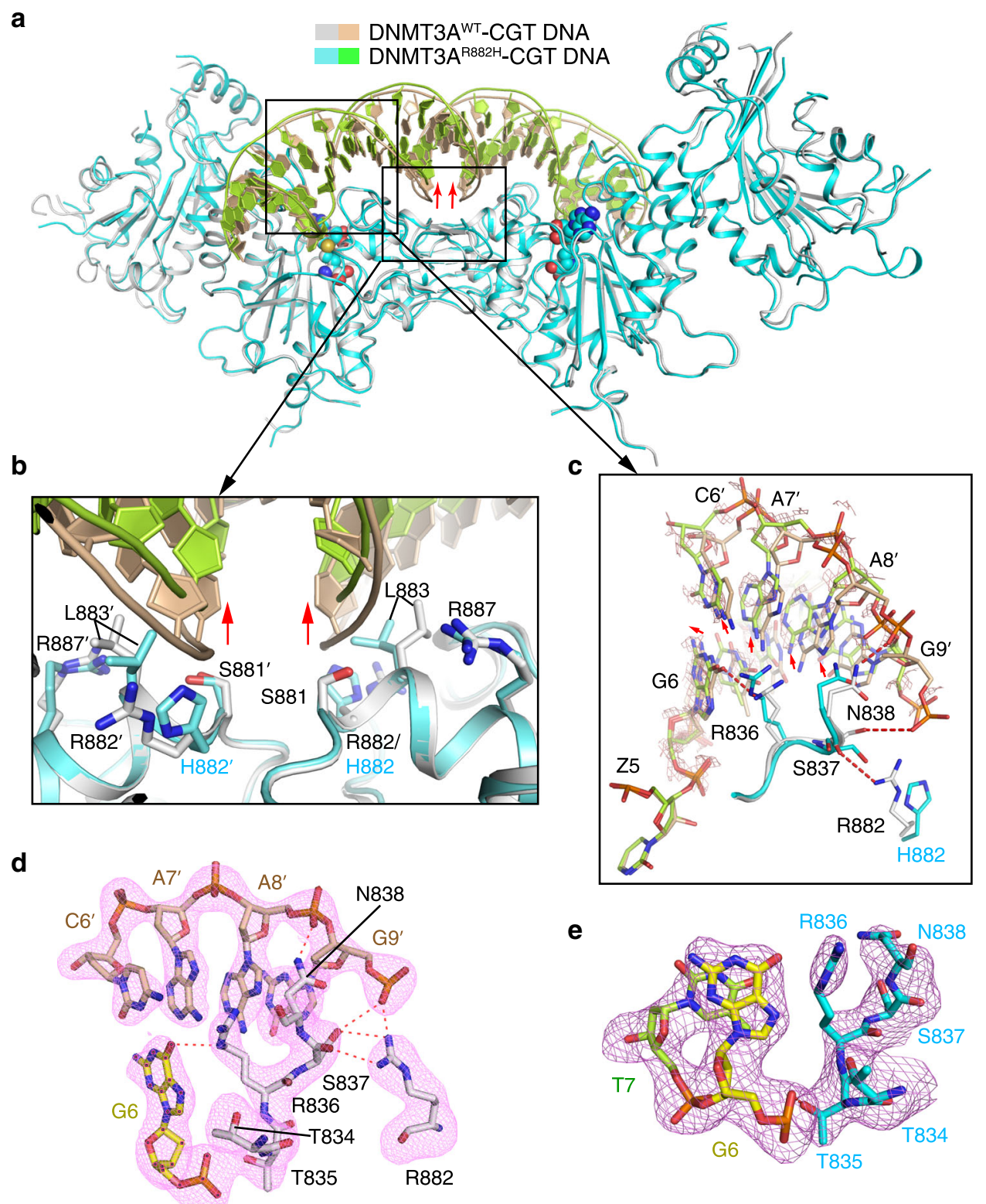

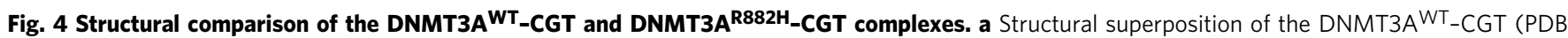
$5 Y X 2)$ and DNMT3AR882H_CGT complexes. b Close-up view of protein-DNA interactions on the RD interface of the DNMT3AWT-CGT and DNMT3A ${ }^{R 882 H}$-CGT complexes. c Close-up view of the TRD loop and its interactions with CpG guanine (G6) and R882 in the DNMT3AWT-CGT and DNMT3AR882H_CGT complexes in expanded view. The hydrogen-bonding interactions are indicated by dashed lines. The conformational shifts of the DNA between the two complexes are validated by the 1.0 sigma Fo-Fo difference map (salmon) between the two complexes and indicated by arrows. $\mathbf{d}$, e Closeup view of the interactions between the TRD loop and DNA in the DNMT3AWT_CGT (PDB 5YX2) (d) and DNMT3A R882H-CGT (e) complexes. The Fo-Fc omit map (violet) for the corresponding regions were contoured at 2.0 sigma level.

(Fig. $4 \mathrm{~b}$ and Supplementary Fig. 3c). As a result of these structural changes, protein-DNA contact at the $\mathrm{RD}$ interface in the DNMT3A $\mathrm{A}^{\mathrm{R} 882 \mathrm{H}}$-CGT complex accounts for a buried surface area of $\sim 206 \AA^{2}$ only, much less than that for the DNMT3A ${ }^{\mathrm{WT}}$-CGT complex.

The molecular environment for the TRD loop between the

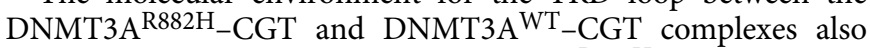

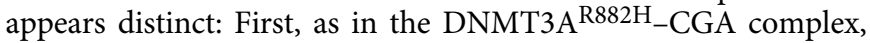
the intramolecular hydrogen bond formed between residues $\mathrm{S} 837$ and R882 in the DNMT3A ${ }^{\mathrm{WT}}$-CGT complex becomes abolished in the DNMT3 $\mathrm{A}^{\mathrm{R} 882 \mathrm{H}}$-CGT complex (Fig. 4c). Second, the DNA molecules in the DNMT3A ${ }^{\mathrm{R} 882 \mathrm{H}}-\mathrm{CGT}$ and DNMT3A $\mathrm{A}^{\mathrm{WT}}-\mathrm{CGT}$ complexes show differential extent of helical twist (Fig. 4c): In comparison with the DNMT3A ${ }^{\mathrm{WT}}$-CGT complex, the DNA major groove in the DNMT3A $\mathrm{A}^{\mathrm{R} 82 \mathrm{H}}$-CGT complex is positioned further away from the TRD loop (Fig. 4c). In line with these environmental changes, the DNMT3A $\mathrm{A}^{\mathrm{R} 82 \mathrm{H}}-\mathrm{CGT}$ and the DNMT3A WT_CGT complex manifests distinct dynamics on the TRD loop: the electron density for the side chains of R836 and $\mathrm{N} 838$ in the DNMT3A $\mathrm{R}^{\mathrm{R} 82 \mathrm{H}}-\mathrm{CGT}$ complex becomes either barely traceable or significantly reduced than their counterpart in the DNMT3A ${ }^{W T}$-CGT complex (Fig. 4d,e). Consistently, the averaged B-factor for residues R836-N838 (119.8 $\left.\AA^{2}\right)$ is significantly higher than the overall averaged $\mathrm{B}$-factor $\left(89.9 \AA^{2}\right)$ of DNMT3A $\mathrm{A}^{\mathrm{R} 82 \mathrm{H}}$ in the DNMT3A $\mathrm{A}^{\mathrm{R} 882 \mathrm{H}}-\mathrm{CGT}$ complex. It is worth noting that the overall B-factor of DNMT3A $\mathrm{A}^{\mathrm{R} 82 \mathrm{H}}$ in the DNMT3A $\mathrm{A}^{\mathrm{R} 822 \mathrm{H}}$-CGT complex is also much higher than that of DNMT3A ${ }^{\mathrm{WT}}$ in the DNMT3A ${ }^{\mathrm{WT}}$-CGT complex $\left(89.9 \AA^{2}\right.$ vs 
a CAG $5^{\prime}--C_{1} A_{2} T_{3} G_{4} Z_{5} A_{6} G_{7} T_{8} C_{9} T_{10} A_{11} A_{12} T_{13} T_{14} A_{15} G_{16} A_{17} C_{18} T_{19} G_{20} C_{21} A_{22} T_{23} G_{24} G_{25}-3^{\prime}$

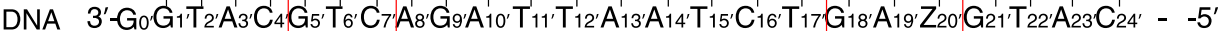

b

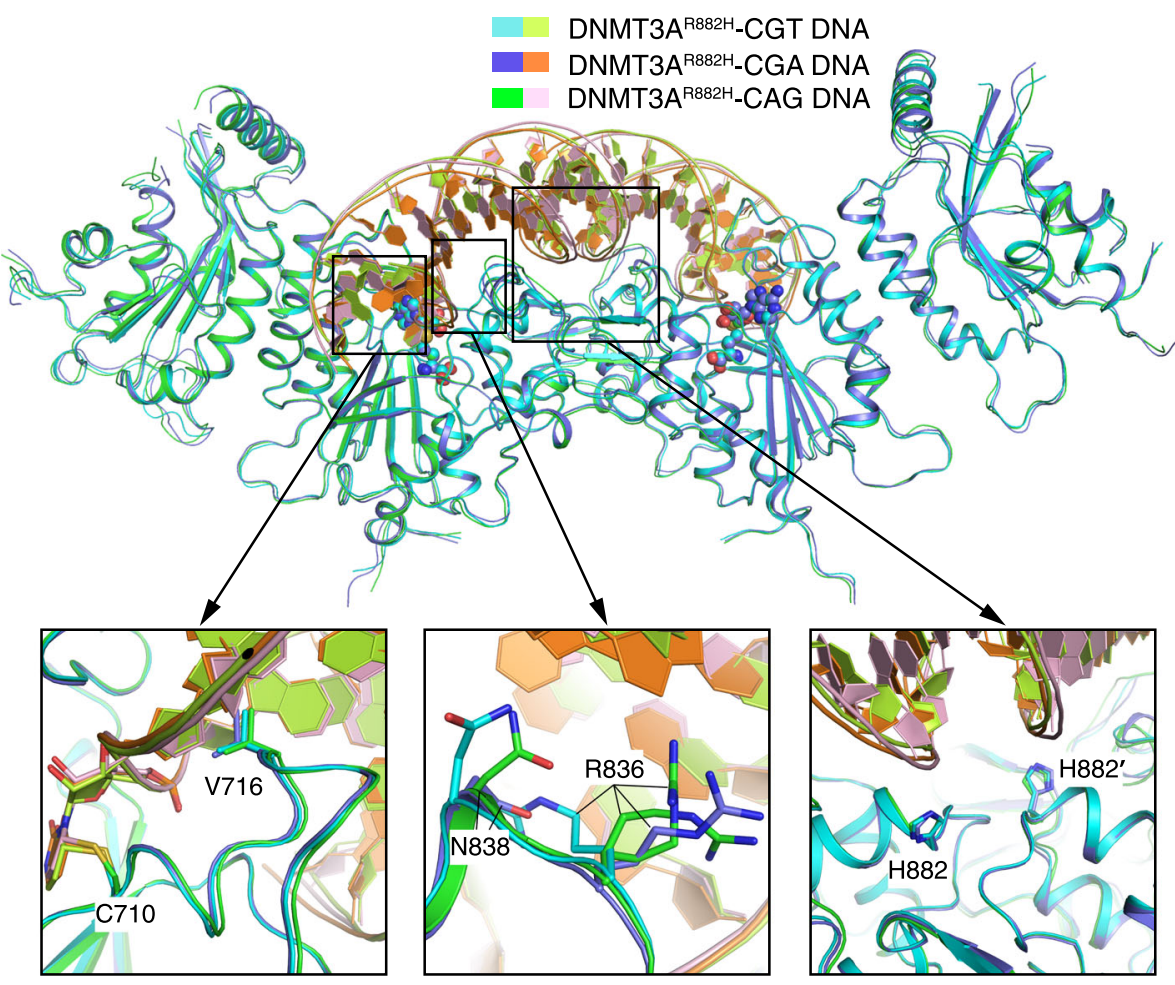

Catalytic loop

TRD loop

RD interface

c

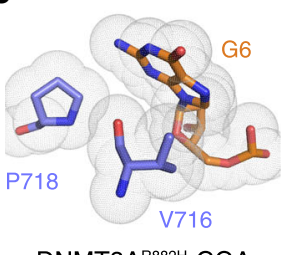

d

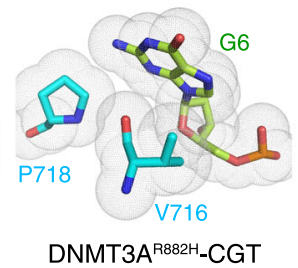

e

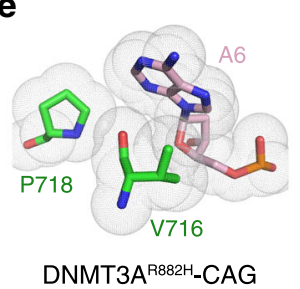

$\mathbf{f}$

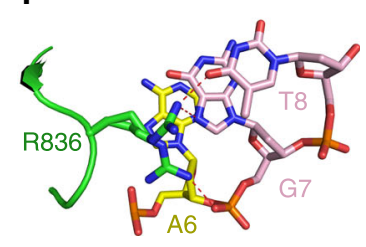

Fig. 5 Structural analysis of the DNMT3A $\mathbf{R}^{\mathbf{R 8 2 2}}$-CAG complex. a DNA sequence (CAG) used for the structural study. $\mathbf{b}$ Structural superposition of the DNMT3A $A^{R 82 H}-C G A, D N M T 3 A^{R 882 H}-C G T$ and DNMT3A ${ }^{R 882 H}-C A G$ complexes, with the aligned catalytic loops, TRD loops and RD interfaces shown in expanded views. The side chains of the DNA-contacting residues are shown in stick representation. c-e van der Waals contacts between the catalytic loop

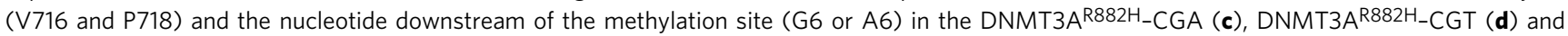
DNMT3A $\mathrm{R}^{\mathrm{R} 82 \mathrm{H}}$-CAG (e) complexes. $\mathbf{f}$ Close-up views of the interaction between TRD residue R836, with two alternative conformations, and the CAG DNA. The hydrogen-bonding interactions are shown as dashed lines.

$62.5 \AA^{2}$ ), despite their similar resolution and crystallization packing. Nevertheless, such structural and dynamic changes between the two complexes reinforce the notion on the interplay between the dynamics of TRD loop and DNA binding ${ }^{24}$, and suggest an impairment of $\mathrm{CpG}$ recognition in the DNMT3A $\mathrm{A}^{\mathrm{R} 82 \mathrm{H}}-\mathrm{CGT}$ complex.

Structural analysis of the DNMT3A ${ }^{\mathrm{R} 882 \mathrm{H}}$-CAG DNA complex. It has been established that DNMT3A not only mediates CpG methylation, but also catalyzes non-CpG methylation, with the enzymatic preference following an order of $\mathrm{CpG}>\mathrm{CpA}>\mathrm{CpT}^{29-33}$. We therefore asked how the conformation of the TRD loop of DNMT3A $\mathrm{A}^{\mathrm{R} 82 \mathrm{H}}$ interplays with non-CpG DNA. To address this question, we determined a $2.45 \AA$-resolution crystal structure of

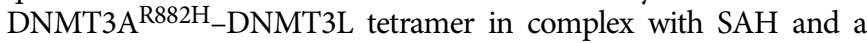
25-mer DNA duplex containing two separate ZpApG sites, mimic of two CpApG sites (Fig. 5a,b and Supplementary Table 1). Structural

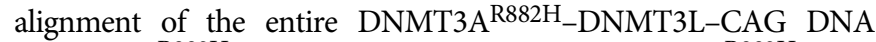
(DNMT3A $\left.{ }^{\mathrm{R} 882 \mathrm{H}}-\mathrm{CAG}\right)$ complex with the DNMT3A ${ }^{\mathrm{R} 882 \mathrm{H}}-\mathrm{CGT}$

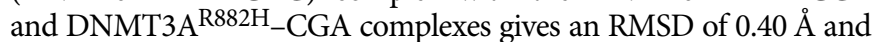
$0.41 \AA$ over 845 an 827 aligned $\mathrm{Ca}$ atoms, respectively, highlighting their structural similarity (Fig. 5b). Consistently, structural comparison of the three DNMT3A ${ }^{\mathrm{R} 882 \mathrm{H}}$-DNA complexes reveals similar DNA binding sites, formed by the catalytic loop, TRD loop and the RD interface (Fig. 5b). In particular, the catalytic loop in the

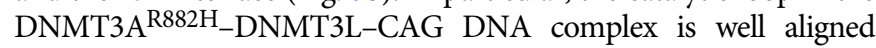
with the corresponding region in the CGT and CGA DNA complexes, with residue V716 moving into the DNA cavity vacated by the base flipping of zebularine to stack against the $\mathrm{ZpA}$ adenosine (A6) (Fig. 5b and Supplementary Fig 4b,c). Nevertheless, due to the different base ring sizes, A6 in the CAG complex engages less van der Waals contact with the catalytic loop residues (V716 and P718) than the corresponding G6 in the CGA and CGT complexes (Fig. $5 \mathrm{c}-\mathrm{e}$ ), which may contribute to the reduced methylation efficiency of DNMT3A on CpA over CpG. Furthermore, the RD 
interface is also well aligned among the three complexes, with the side chain of residue $\mathrm{H} 882$ poised in a similar conformation (Fig. 5b). Accordingly, the protein-DNA contact at the RD interface of the DNMT3A $\mathrm{R}^{\mathrm{R} 82 \mathrm{H}}-\mathrm{CAG}$ complex leads to a buried surface area of $\sim 207 \AA^{2}$, comparable with that in the DNMT3A $\mathrm{A}^{\mathrm{R} 882 \mathrm{H}}-\mathrm{CGT}$ and DNMT3A $\mathrm{R}^{\mathrm{R} 82 \mathrm{H}}$-CGA DNA complexes. The structural similarity between the CpA and CpG DNA complexes of DNMT3A $\mathrm{A}^{\mathrm{R} 82 \mathrm{H}}$ indicate that DNMT3A mediates $\mathrm{CpA}$ methylation in a similar fashion as it does for the CpG methylation, highlighting its conserved catalytic mechanism in DNA methylation, as well as the structural rigidity of the DNMT3 $\mathrm{A}^{\mathrm{R} 882 \mathrm{H}}-\mathrm{DNMT} 3 \mathrm{~L}$ tetramer.

Similar to what was observed for the DNMT3A R882H $_{-C G A}$ complex, the side chain of R836 points toward the $+1-+2$ flanking nucleotides, albeit with two alternative conformations: one $\mathrm{R} 836$ conformer approaches the $\mathrm{O} 4$ atom of $\mathrm{T} 8$ for hydrogen bond formation, while the other points toward the backbone phosphate of G7 to form a salt bridge (Fig. 5b,f). However, unlike the DNMT3A ${ }^{\mathrm{R} 882 \mathrm{H}}$-CGA DNA complex in which N838 forms base-specific hydrogen bond with $\mathrm{CpG}$ guanine, the equivalent residue in the DNMT3 $\mathrm{A}^{\mathrm{R} 882 \mathrm{H}}-\mathrm{CAG}$ complex is not involved in any contact with DNA (Fig. 5b and Supplementary Fig. 4d). These observations further suggest the conformational flexibility of the TRD loop of DNMT3A $\mathrm{R}^{882 \mathrm{H}}$ in accommodating the DNA substrates in different sequence contexts, and reinforce the notion that enhanced conformational dynamics of the TRD loop by the $\mathrm{R} 882 \mathrm{H}$ mutation impairs CpG-specific DNA methylation. It is worth noting that a water-mediated hydrogen bond is formed between the side chain of T834 and the N7 atom of A6 in the DNMT3A ${ }^{\mathrm{R} 822 \mathrm{H}}$-CAG complex (Supplementary Fig. 4d), resembling the interaction between T834 and the CpG guanine in the DNMT3A-CpG complexes (Figs. $1 \mathrm{~d}$ and $3 \mathrm{~d})^{24}$. Given the fact that a thymine base lacks the corresponding N7 group, this interaction may underpin the differential methylation efficiency of DNMT3A on CpA- and CpT-containing DNAs.

Structural integrity of the RD interface. Structural analysis of the three DNMT3A $882 \mathrm{H}_{-} \mathrm{DNA}$ complexes reveals that the $\mathrm{RD}$ interface is maintained in the same fashion as the DNMT3A WT_DNA complexes, dominated by the reciprocal salt bridges formed between residue R885 from one DNMT3A monomer and residue D876 from the symmetry-related mate (Supplementary Fig. 5a-e). These observations therefore suggest that the RD interface-mediated homodimerization is preserved in DNMT3A $\mathrm{A}^{\mathrm{R} 82 \mathrm{H}}$, consistent with previous biochemical studies that this residue does not directly contribute to the formation of DNMT3A homodimer in the context of the DNMT3A-DNMT3L tetramer $24,26,27$. The caveat of this observation is that it concerns only the structure of DNTM3A $\mathrm{A}^{\mathrm{R} 82 \mathrm{H}}$ complexed with DNMT3L, a regulatory factor that is under-expressed in somatic tissues ${ }^{8}$. Therefore, the effect of the $\mathrm{R} 882 \mathrm{H}$ mutation on the oligomerization of DNMT3A in hematopoietic stem cells awaits further investigation.

DNA-binding and enzymatic analysis of DNMT3A ${ }^{\text {R822H }}$. Given that the structures of the DNMT3A $\mathrm{A}^{\mathrm{R} 822 \mathrm{H}}$-DNA complexes suggest that the $\mathrm{R} 882 \mathrm{H}$ mutation might lead to impaired DNA contact at both the RD interface and the TRD loop, we next performed biochemical and enzymatic analyses to evaluate the functional consequence of the $\mathrm{R} 882 \mathrm{H}$ mutation. First, we compared the DNA binding activities of the DNMT3 $\mathrm{A}^{\mathrm{WT}}-\mathrm{DNMT} 3 \mathrm{~L}$ tetramer and DNMT3A ${ }^{\mathrm{R} 882 \mathrm{H}}$-DNMT3L tetramer for a 36-mer CpG DNA using electrophoretic mobility shift assay (EMSA). Consistent with what previously reported ${ }^{27}$, titration of the DNA with the DNMT3A $\mathrm{WT}^{\mathrm{WT}}$-DNMT3L tetramer led to the appearance of multiple slow-mobility bands that correspond to the DNMT3A ${ }^{\mathrm{WT}}$-DNMT3L-DNA complexes with various stoichiometric ratios (Fig. 6a). By contrast, significantly reduced gel shift was observed for the DNMT3A $\mathrm{R}^{\mathrm{R} 82 \mathrm{H}}$-DNMT3L tetramer (Fig. 6a). Furthermore, we performed isothermal titration calorimetry (ITC) binding assays to compare the binding affinities of DNMT3A ${ }^{\text {WT }}$-DNMT3L and DNMT3A ${ }^{\text {R882H_DNMT3L }}$ for a 24-mer CpG DNA. DNMT3A ${ }^{\mathrm{WT}}$-DNMT3L binds to the DNA with dissociation constant $\left(K_{\mathrm{d}}\right)$ of $9.8 \mu \mathrm{M}$; under the same experimental condition, no appreciable DNA binding was

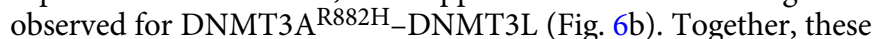
data confirm that the $\mathrm{R} 882 \mathrm{H}$ mutation leads to reduced DNAbinding affinity of DNMT3A.

Next, we performed in vitro enzymatic analysis to evaluate the effect of the $\mathrm{R} 882 \mathrm{H}$ mutation on the enzymatic activity and specificity of DNMT3A. Toward this, we measured the enzymatic activities of DNMT3A ${ }^{\text {WT }}$-DNMT3L and DNMT3A ${ }^{\text {R882H }}$ DNMT3L on CG-, CA- and CT-containing DNAs (Supplementary Fig. $6 \mathrm{c}-\mathrm{g}$ ). Under the experimental condition, the R882H mutation reduced the activity of DNMT3A on CG-containing DNA by 3.3-fold (Supplementary Fig. 6c), consistent with previous observations that this mutation reduces the enzymatic activity of DNMT3A $17,20-22,24$. By contrast, the methylation activity of DNMT3A ${ }^{\text {R882H }}$ on CA-containing DNA was reduced by 1.3 -fold, and was increased by 1.3 -fold on CT-containing DNA. (Supplementary Fig. 6d). As a result, the relative preferences of DNMT3A for CG/CA and CG/CT DNAs were reduced by 2.6- and 4.2-fold, respectively (Fig. $6 \mathrm{c}$ ). To evaluate the effect of the $\mathrm{R} 882 \mathrm{H}$ mutation on the DNMT3A activities toward CpG and non-CpG sites located on the same DNA substrate, we also measured the enzymatic activities of DNMT3A ${ }^{\text {WT }}$-DNMT3L and DNMT3A ${ }^{\text {R } 882 H_{-}}$ DNMT3L on a 626-bp long DNA substrate, containing multiple $\mathrm{CpG}, \mathrm{CpA}, \mathrm{CpT}$, and $\mathrm{CpC}$ sites. To allow for accurate comparison of CpG specificity, the protein levels and reaction times

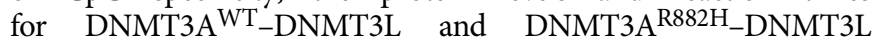
were adjusted to achieve a similar level of $\mathrm{CpG}$ methylation. After methylation reaction with DNMT3A $\mathrm{WT}_{-\mathrm{DNMT} 3 \mathrm{~L} \text { or }}$ DNMT3A ${ }^{\mathrm{R} 882 \mathrm{H}}$-DNMT3L, the DNA substrates were subjected to bisulfite sequencing analysis. As expected for the high $\mathrm{CpG} /$ nonCpG specificity of DNMT3A ${ }^{24,29}$, the DNA substrates methylated by DNMT3A ${ }^{\text {WT }}$-DNMT3L show dominant CpG methylation over $\mathrm{CpH}(\mathrm{H}=\mathrm{A}, \mathrm{C}$, or $\mathrm{T})$ methylation (Fig. 6d and Supplementary Fig. 6h). In comparison, the DNA substrates methylated by

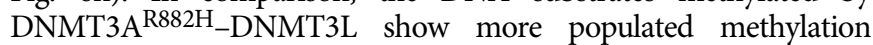
events on $\mathrm{CpH}$ sites, with significantly increased $\mathrm{CpA}$ and $\mathrm{CpC}$ methylation (Fig. 6d and Supplementary Fig. 6h). Furthermore, analysis of the relative methylation levels of the CGX $(X=G, A, T$ or C) motif in the DNA substrate also indicates that the $\mathrm{R} 882 \mathrm{H}$ mutation shifts the relative methylation efficiencies of DNMT3A ${ }^{\text {WT }}$-DNMT3L toward the CG(G/A) sites (Supplementary Fig. 6i), consistent with the observation in a recent report ${ }^{25}$ Together, these data lend a strong support to the structural observation that the $\mathrm{R} 882 \mathrm{H}$ mutation results in impaired $\mathrm{CpG}$ recognition of DNMT3A.

\section{Discussion}

DNA methylation is an essential epigenetic mechanism that critically regulates gene expression, genomic stability, and cell lineage commitment. Dysregulation of DNA methyltransferases is linked to a variety of human diseases, with DNMT3A mutations particularly implicated in hematological cancers and DNMT3B mutations associated with ICF syndrome ${ }^{34}$. A detailed understanding of the structural and functional consequences of DNMT3A or DNMT3B mutations is vital to deciphering their 
a

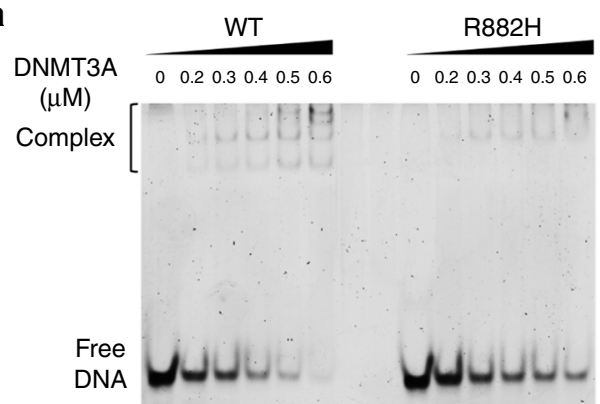

C

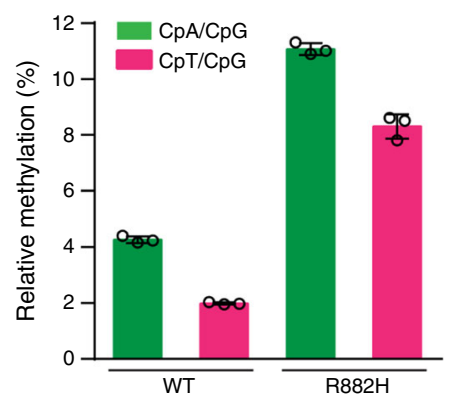

b

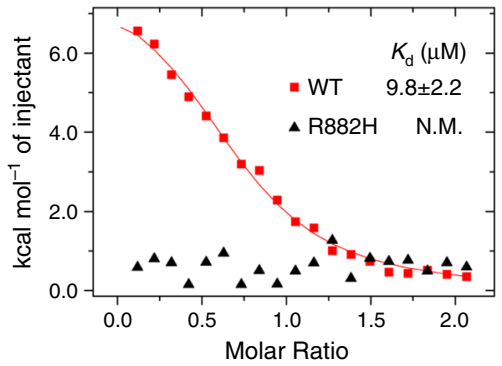

d

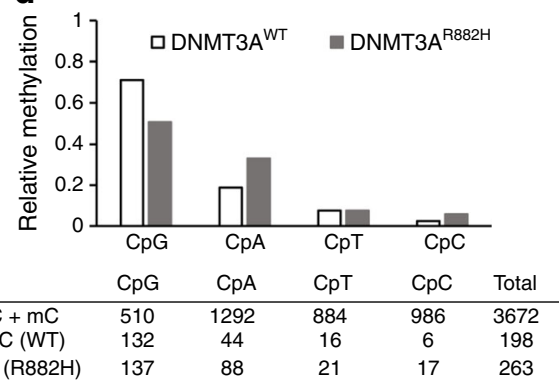

e

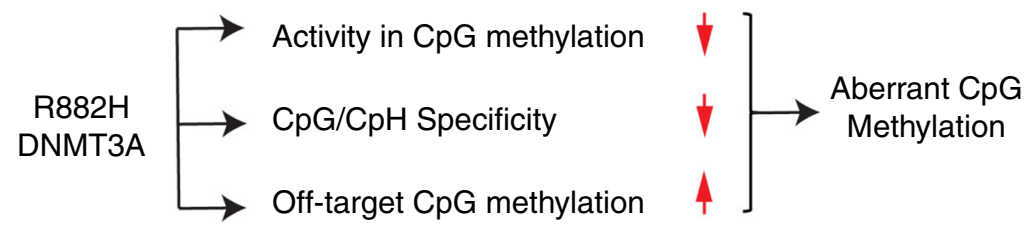

Fig. 6 Biochemical and enzymatic analyses of the DNMT3A R882H$^{-D N A}$ interaction. a EMSA gel image of the DNA binding activities of WT and R882Hmutated DNMT3A-DNMT3L on 36-mer (GAC) 12 DNA. Source data are provided as a Source Data file. The experiment was repeated once with consistent results. $\mathbf{b}$ ITC binding analysis of WT and R882 H-mutated DNMT3A-DNMT3L on 24-mer (GAC) 8 DNA. The data and error estimate were derived from two independent experiments. N.M., not measurable. $\mathbf{c}$ In vitro $\mathrm{CpG}$ and $\mathrm{CpH}$ methylation of WT and R882H-mutated DNMT3A-DNMT3L, using a 36-mer DNA containing a single CpG, CpA or CpT site ( $n=3$ biological replicates). The data are displayed as ratios of $\mathrm{CpA} / \mathrm{CpG}$ and $\mathrm{CpT} / \mathrm{CpG}$ methylation. Data are mean \pm s.d. Source data are provided as a Source Data file. d (Top) Relative in vitro $\mathrm{CpG}$ and $\mathrm{CpH}$ methylation of WT and R882H-mutated DNMT3A-DNMT3L on a 626-bp DNA. The data are displayed as ratios of the methylation events of each indicated sequence context over total methylation events. (Bottom) Summary of total cytosine sites and methylation events in each indicated context, derived from bisulfite sequencing analyses of 34 clones of the 626-bp DNA incubated with WT or R882H-mutated DNMT3A-DNMT3L. Source data are provided as a Source Data file. e Model for the impairment of $\mathrm{CpG}$ methylation by the DNMT3A R882H mutation.

pathological effect, which will ultimately benefit the development of novel therapeutic strategies against diseases. This study, through structural and biochemical characterizations of DNMT3A ${ }^{\mathrm{R} 882 \mathrm{H}}$-DNA interaction, reveals multiple functional impacts of the AML-associated hotspot mutation DNMT3A $\mathrm{R} 882 \mathrm{H}$ : The R882H mutation not only reduced the protein-DNA interactions at the $\mathrm{RD}$ interface, but also impairs the TRD loopmediated CPG recognition, which may together contribute to aberrant $\mathrm{CpG}$ methylation in AML.

Importantly, this study uncovers the interplay between the intrinsic conformational dynamics of the TRD loop of DNMT3A and its $\mathrm{CpG}$ recognition. In particular, the DNMT3A $\mathrm{WT}_{-}$CGA complex presented in this study, along with the DNMT3A ${ }^{\mathrm{WT}}$-CGT complex we reported previously ${ }^{24}$, reveals that residues R836-N838 of the TRD loop adopt different conformations when binding to DNA substrates with different sequence contexts, highlighting the conformational flexibility of this region. In the DNMT3A ${ }^{\mathrm{WT}}$-CGT complex, R836 forms a base-specific hydrogen bond with the O6 atom of $\mathrm{CpG}$ guanine, which ensures the $\mathrm{CpG}$ specificity, as described previously ${ }^{24}$. However, in the DNMT3A ${ }^{\mathrm{WT}}$-CGA complexes, R836 turns away from the $\mathrm{CpG}$ site to form a hydrogen bond with the $+1 \mathrm{~A}$, as well as +2 or +3 flanking nucleotides.
Meanwhile, the side chain of N838 turns to the position vacated by the side chain of R836 to form the base-specific hydrogen bond with the $\mathrm{O} 6$ atom of $\mathrm{CpG}$ guanine, which presumably compensates for the loss of R836-medated CpG recognition. Conceivably, these alternative $\mathrm{CpG}$ recognition modes provide a mechanism by which DNMT3A senses the flanking sequence of CpG sites, which may play a role in fine-tuning the DNA methylation patterns across the genome. A full understanding of these alternative $\mathrm{CpG}$ recognition modes awaits further investigation.

This study also reveals the crosstalk between the RD interface and the TRD loop of DNMT3A. Introduction of the R882H mutation reduces the interactions between the $\mathrm{RD}$ interface and DNA. As a result, the DNA molecule in the DNMT3A $A^{\mathrm{R} 822 \mathrm{H}}-\mathrm{DNA}$ complex bends further away from the RD interface, and the hydrogen bond between R882 and 5837 becomes disrupted. These structural changes may together contribute to the mobilization of the TRD loop, thereby impairing the context-dependent CpG recognition by DNMT3A. Along the line, the enzymatic preference toward the flanking sequences of $\mathrm{CpG}$ target sites has previously been observed for both DNMT3A and DNMT3B 35 -38, yet the mechanism remains unclear. The enzymatic analysis in this study not only supports an earlier notion that the DNMT3A R882H 
mutation shifts the enzymatic preference of DNMT3A toward a purine ( $G$ or $A$ ) on the +1 flanking $\operatorname{sit}^{25}$ (Supplementary Fig. $6 \mathrm{~d}$ ), but also indicates that the $\mathrm{R} 882 \mathrm{H}$ mutation reduces the $\mathrm{CpG} / \mathrm{CpH}$ specificity of DNMT3A, both of which presumably impact the DNA methylation landscape across the genome ${ }^{25}$. Importantly, the crosstalk between the RD interface and the TRD loop provides a mechanism by which the $\mathrm{R} 882 \mathrm{H}$ mutation affects the substrate specificity of DNMT3A. It is also conceivable that similar conformational changes in the TRD loop and $\mathrm{RD}$ interface can also be induced by the R882C mutation, a second most prominent missense mutation of DNMT3A in AML, and other R882 mutations ${ }^{13}$.

The observation that the DNMT3A R882H mutation impacts the context-dependent DNA methylation suggests this mutation might impair the cellular $\mathrm{CpG}$ methylation through multiple pathways (Fig. 6e): (1) the R882H mutation directly reduces the CpG methylation activity of DNMT3A; (2) the R882H mutation may influence the flanking sequence preference of DNMT3A, resulting in aberrant DNA methylation patterns; and (3) the $\mathrm{R} 882 \mathrm{H}$ mutation may shift the events of the cytosine methylation toward non-CpG methylation, which would be subjected to immediate elimination during replication-dependent maintenance DNA methylation by DNMT1, an enzyme that shows strict CpG specificity ${ }^{5,39-42}$. Collectively these functional defects of the R882H-mutated DNMT3A might contribute to the aberrant DNA methylation in AML.

\begin{abstract}
Methods
Protein expression and purification. DNA fragments encoding the C-terminal domains of WT or R882H-mutated DNMT3A (residues 628-912) and DNMT3L (residues 178-386) were inserted in tandem into pRSFDuet-1 vector (Novagen) containing an N-terminal $\mathrm{His}_{6}$-SUMO tag (See Supplementary Table 2 for primer information). The DNMT3A ${ }^{\text {WT }}$-DNMT3L and DNMT3A ${ }^{\text {R8 } 82 \mathrm{H}}$-DNMT3L complexes were expressed in Escherichia coli BL21 DE3 (RIL) cells, as described previously ${ }^{24}$, followed by purification using a $\mathrm{Ni}^{2+}$-NTA affinity column, with buffer A (50 mM Tris-HCl, pH 8.0, $1 \mathrm{M} \mathrm{NaCl}$ and $25 \mathrm{mM}$ imidazole) used for sample loading and wash, and buffer B (50 mM Tris-HCl, $\mathrm{pH} 8.0,1 \mathrm{M} \mathrm{NaCl}$ and $300 \mathrm{mM}$ imidazole) for elution. Upon removing the $\mathrm{His}_{6}$-SUMO tag via Ubiquitin-like protease 1 (ULP1)-mediated cleavage the protein complex was further purified via $100-600 \mathrm{mM} \mathrm{NaCl}$ gradient on a Heparin column (low salt buffer: $25 \mathrm{mM}$ Tris$\mathrm{HCl}, \mathrm{pH}$ 8.0, and $100 \mathrm{mM} \mathrm{NaCl}$; high salt buffer: $25 \mathrm{mM}$ Tris-HCl, $\mathrm{pH}$ 8.0, and $1 \mathrm{M}$ $\mathrm{NaCl}$ ), and size-exclusion chromatography on a $16 / 600$ Superdex $200 \mathrm{pg}$ column (GE Healthcare) in buffer containing $20 \mathrm{mM}$ Tris- $\mathrm{HCl}$ (pH 8.0), $100 \mathrm{mM} \mathrm{NaCl}$, $0.1 \% \beta$-mercaptoethanol and $5 \%$ glycerol. The purified DNMT3A ${ }^{\mathrm{WT}}$-DNMT3L or DNMT3A ${ }^{\mathrm{R} 882 \mathrm{H}_{-}}$DNMT3L tetramer was concentrated to $0.3 \mathrm{mM}$ and stored in $-80^{\circ} \mathrm{C}$ freezer before use.
\end{abstract}

Preparation of enzyme-substrate covalent complexes. 25-mer self-complementary DNA sequences were used for generation of the DNMT3A $\mathrm{R}^{\mathrm{R} 82 \mathrm{H}}$ DNMT3L-CGT (CGT DNA: 5'-GCATGZGTTCTAATTAGAACGCATG-3'; Z = zebularine), DNMT3A ${ }^{\text {WT }}$-DNMT3L-CGA and DNMT3A ${ }^{\text {R882H }}$-DNMT3L-CGA (CGA DNA: 5'-CATGZGATCTAATTAGATCGCATGG-3'; $Z=$ zebularine) and DNMT3A R882H_DNMT3L-CAG (CAG DNA: 5'-CATGZAGTCTAATTAGACT GCATGG-3'; Z = zebularine) complexes. The DNA molecules were first subject to a denaturation and annealing process to generate duplexed DNA samples. Subsequently, the DNA was incubated with the DNMT3A ${ }^{\text {WT }}$-DNMT3L or DNMT3A ${ }^{\mathrm{R} 882 \mathrm{H}}$-DNMT3L tetramer in a 1:1 molar ratio to allow complex formation in a buffer containing $20 \mathrm{mM}$ Tris- $\mathrm{HCl}(\mathrm{pH} 8.0), 20 \%$ glycerol and $40 \mathrm{mM}$ DTT. The reaction products were sequentially purified via $100-600 \mathrm{mM} \mathrm{NaCl}$ gradient on a HiTrap Q XL column (GE Healthcare) (low salt buffer: $25 \mathrm{mM}$ Tris-HCl, $\mathrm{pH}$ 8.0, $20 \mathrm{mM}$ DTT and $100 \mathrm{mM} \mathrm{NaCl}$; high salt buffer: $25 \mathrm{mM}$ Tris- $\mathrm{HCl}$, pH 8.0, $20 \mathrm{mM}$ DTT and $1 \mathrm{M} \mathrm{NaCl}$ ) and size-exclusion chromatography on a 16/600 Superdex $200 \mathrm{pg}$ column (GE Healthcare) in buffer containing $20 \mathrm{mM}$ Tris- $\mathrm{HCl}$ (pH 8.0), $100 \mathrm{mM} \mathrm{NaCl}, 0.1 \% \beta$-mercaptoethanol and $5 \%$ glycerol. The final protein samples of the DNMT3A ${ }^{\text {WT }}$-DNMT3L-DNA and DNMT3A ${ }^{\text {R882H}}$-DNMT3L-DNA complexes were concentrated to $0.1 \mathrm{mM}$ and used for crystallization.

\section{Crystallization conditions and structure determination. Crystals for} DNMT3A ${ }^{\text {WT }}$-DNMT3L-CGA, DNMT3A ${ }^{\text {R882H}}$-DNMT3L-CGA and DNMT3A ${ }^{\mathrm{R} 882 \mathrm{H}}$-DNMT3L-CGT complexes were generated using hanging-drop vapor-diffusion method at $4{ }^{\circ} \mathrm{C}$, from drops containing $0.2 \mu \mathrm{L}$ of $0.1 \mathrm{mM}$ complex sample mixed with $0.8 \mu \mathrm{L}$ of precipitant solution ( $0.1 \mathrm{M}$ Sodium Citrate $\mathrm{pH} 4.2,1 \%$ PEG8000). Crystals for the DNMT3A R882H-DNMT3L-CAG complex were generated using hanging-drop vapor-diffusion method at $4{ }^{\circ} \mathrm{C}$, from drops containing $0.5 \mu \mathrm{L}$ of $0.1 \mathrm{mM}$ DNMT3A ${ }^{\mathrm{R} 882 \mathrm{H}}-\mathrm{DNMT} 3 \mathrm{~L}-\mathrm{CAG}$ complex sample and $0.5 \mu \mathrm{L}$ of precipitant solution (0.1 M Sodium Citrate $\mathrm{pH} 4.4,0.2 \%$ PEG8000). The crystals were soaked in cryoprotectant made of mother liquor and 35\% glycerol before harvesting. X-ray diffractions datasets for the DNMT3A ${ }^{\text {R } 822 \mathrm{H}}$-DNMT3L-CGA complex were collected on the BL12-2 beamline at the Stanford Synchrotron Radiation Light source (SSRL), SLAC National Accelerator Laboratory. X-ray diffractions datasets for the DNMT3A ${ }^{\mathrm{WT}}$-DNMT3L-CGA, DNMT3A ${ }^{\text {R882H}}$-DNMT3L-CGT and DNMT3A ${ }^{\text {R882H}}$-DNMT3L-CAG complexes were collected on the beamline 5.0.1 or 5.0.2 at the Advanced Light Source (ALS), Lawrence Berkeley National Laboratory. The diffraction data were indexed, integrated, and scaled using the HKL 3000 program ${ }^{43}$. The structures of the complexes were solved by molecular replacement with the PHASER ${ }^{44}$ module in the PHNIEX software package ${ }^{45}$, using the structure of DNMT3A ${ }^{\text {WT }}$-DNMT3L-CGT DNA complex (PDB 5YX2) as search model. The structural models of the DNMT3A ${ }^{\text {WT }}$-DNMT3L-CGA and DNMT3A ${ }^{\text {R882H}}$-DNMT3L-DNA complexes were then subjected to modification using $\mathrm{COOT}^{46}$ and refinement using the PHENIX software package ${ }^{45}$ in an iterative manner. The same R-free test set was used throughout the refinement. The statistics for data collection and structural refinement of the productive covalent DNMT3A ${ }^{\text {WT }}$-DNMT3L-CGA and DNMT3A ${ }^{\mathrm{R} 882 \mathrm{H}}$-DNMT3L-DNA complexes are summarized in Supplementary Table 1.

In vitro radioactivity-based methylation assay. In vitro methylation assay was performed in triplicates using $20-\mu \mathrm{L}$ reactions containing $1 \mu \mathrm{M}$ protein (either DNMT3A ${ }^{\text {WT }}$-DNMT3L or DNMT3A ${ }^{\text {R882H}}$-DNMT3L), $1 \mu \mathrm{M}$ 36-mer DNA substrate with a single CG, CA, or CT site (5'-AATAATAATAATAATAACXATA ATAATAATAATAAA- $3^{\prime}, \mathrm{X}=\mathrm{G}, \mathrm{A}$ or T), $2.5 \mu \mathrm{M} S$-adenosyl-L-[methyl- ${ }^{3} \mathrm{H}$ ] methionine with a specific activity of $18 \mathrm{Ci} / \mathrm{mmol}$ (PerkinElmer), $1.96 \mu \mathrm{M}$ nonradioactive SAM, $50 \mathrm{mM}$ Tris- $\mathrm{HCl}$ ( $\mathrm{pH}$ 7.5), $0.05 \% \beta$-mercaptoethanol, $5 \%$ glycerol and $200 \mu \mathrm{g} / \mathrm{mL}$ BSA. Reactions were left to proceed for 1 hour or indicated times at $37^{\circ} \mathrm{C}$ and stopped by adding $5 \mu \mathrm{L}$ of $10 \mathrm{mM}$ nonradioactive SAM to each reaction. Samples were loaded onto DEAE membrane, washed three times with $0.2 \mathrm{M}$ ammonium bicarbonate ( $\mathrm{pH} 8.2$ ), once with deionized water, and once with $95 \%$ ethanol. The membrane was left to dry for 1 hour, cut into squares to separate samples and soaked in a vial containing $4 \mathrm{~mL}$ of scintillation buffer. The incorporation of tritium onto DNA substrates was measured using Beckman LS6500 counter.

Electrophoretic mobility shift assay. DNA binding analysis was conducted using $20 \mathrm{nM}$ DNA duplex containing $(\mathrm{GAC})_{12}$ repeats which was titrated with either DNMT3A ${ }^{\text {WT }}$-DNMT3L or DNMT3A ${ }^{\mathrm{R} 882 \mathrm{H}}-\mathrm{DNMT} 3 \mathrm{~L}$, with protein concentrations ranged from 0 to $600 \mathrm{nM}$. The binding buffer contained $50 \mathrm{mM}$ Tris- $\mathrm{HCl}(\mathrm{pH}$ 7.5), $5 \%$ glycerol and $1 \mathrm{mM}$ DTT. Samples were resolved on a $4-15 \% \mathrm{wt} / \mathrm{v}$ polyacrylamide gel, which was run at $4^{\circ} \mathrm{C}$ using $17.8 \mathrm{mM}$ Tris-borate (pH 8.3) and $0.4 \mathrm{mM}$ EDTA running buffer.

Bisulfite sequencing analysis of $\mathrm{CpG}$ and $\mathrm{CpH}$ methylation. A 626-bp long DNA substrate (denoted herein as GST3), containing $15 \mathrm{CpG}, 38 \mathrm{CpA}, 26 \mathrm{CpT}$, and $29 \mathrm{CpC}$ sites, was amplified from one DNA fragment of the cDNA sequence encoding glutathione S-transferase gene. $0.05 \mu \mathrm{M}$ GST3 was incubated in a methylation reaction buffer containing $400 \mu \mathrm{M}$ SAM (S-adenosyl-L-methionine), $50 \mathrm{mM}$ Tris- $\mathrm{HCl} \mathrm{pH} \mathrm{7.5,} \mathrm{0.05 \%} \beta$-mercaptoethanol and $5 \%$ glycerol in the absence or presence of either $5 \mu \mathrm{M}$ DNMT3A $\mathrm{A}^{\mathrm{R} 82 \mathrm{H}}-\mathrm{DNMT} 3 \mathrm{~L}$ for $3 \mathrm{~h}$. or $1 \mu \mathrm{M}$ WT DNMT3A ${ }^{\text {WT }}$-DNMT3L for $0.5 \mathrm{~h}$. After incubation, the reactions were stopped by immersing samples in liquid nitrogen. The samples were subjected to bisulfite conversion using EZ DNA Methylation Gold Kit (ZYMO Research). Subsequently the upper strand of the GST3 DNA substrate was PCR amplified, cloned into $\mathrm{pCR}^{\mathrm{m}} 4-\mathrm{TOPO}^{\mathrm{mm}} \mathrm{TA}$ Vector (Invitrogen), and sequenced to determine the level of $\mathrm{CpG}, \mathrm{CpA}, \mathrm{CpT}$, and $\mathrm{CpC}$ methylation. The experiments were performed with two biological replicates. For replicate 1,34 DNA clones were sequenced for methylation analysis of each protein; for replicate 2, 7 DNA clones were sequenced for methylation analysis of each protein. Comparable CpG methylation levels (20$25 \%$ ) between the samples were obtained for analysis. As control, the GST3 DNA incubated in the absence of protein was subjected to bisulfite conversion, PCR amplification and cloning analysis. A bisulfite conversion rate of $98.2 \%$ was determined by the control experiment.

ITC measurements. DNA duplex containing $(\mathrm{GAC})_{8}$ repeats was used to titrate

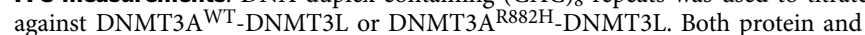
DNA samples were dialyzed against the ITC buffer $(20 \mathrm{mM}$ Tris- $\mathrm{HCl}, \mathrm{pH} 7.5$, $100 \mathrm{mM} \mathrm{NaCl}, 5 \%$ glycerol) at $4{ }^{\circ} \mathrm{C}$ overnight. A MicroCal iTC200 system (GE Healthcare) was used to conduct the ITC measurements. A total of 20 injections with a spacing of $180 \mathrm{~s}$ and a reference power of $5 \mu \mathrm{cal} / \mathrm{s}$ were performed at $4{ }^{\circ} \mathrm{C}$. The ITC curves were processed with software ORIGEN (MicroCal) using one-site fitting model.

Reporting summary. Further information on research design is available in the Nature Research Reporting Summary linked to this article. 


\section{Data availability}

Coordinates and structure factors for DNMT3A WT-DNMT3L-CGA DNA, DNMT3A ${ }^{\text {R882H}}$-DNMT3L-CGA DNA, DNMT3A ${ }^{\text {R882H}}$-DNMT3L-CGT DNA, DNMT3A ${ }^{\mathrm{R} 882 \mathrm{H}}$-DNMT3L-CAG DNA complexes have been deposited in the Protein Data Bank under accession codes 6W8B, 6W89, 6W8D, and 6W8J, respectively. The source data underlying Fig. 6a,c,d and Supplementary Figs 6e-h are provided as a Source Data file. Other data are available from the corresponding author upon reasonable request.

Received: 11 January 2020; Accepted: 15 April 2020;

Published online: 08 May 2020

\section{References}

1. Law, J. A. \& Jacobsen, S. E. Establishing, maintaining and modifying DNA methylation patterns in plants and animals. Nat. Rev. Genet. 11, 204-220 (2010).

2. Smith, Z. D. \& Meissner, A. DNA methylation: roles in mammalian development. Nat. Rev. Genet. 14, 204-220 (2013).

3. Jabbari, K. \& Bernardi, G. Cytosine methylation and CpG, TpG (CpA) and TpA frequencies. Gene 333, 143-149 (2004).

4. Okano, M., Bell, D. W., Haber, D. A. \& Li, E. DNA methyltransferases Dnmt3a and Dnmt3b are essential for de novo methylation and mammalian development. Cell 99, 247-257 (1999).

5. Goll, M. G. \& Bestor, T. H. Eukaryotic cytosine methyltransferases. Annu. Rev. Biochem. 74, 481-514 (2005).

6. Bourc'his, D., Xu, G. L., Lin, C. S., Bollman, B. \& Bestor, T. H. Dnmt3L and the establishment of maternal genomic imprints. Science 294, 2536-2539 (2001).

7. Chedin, F., Lieber, M. R. \& Hsieh, C. L. The DNA methyltransferase-like protein DNMT3L stimulates de novo methylation by Dnmt3a. Proc. Natl Acad. Sci. USA 99, 16916-16921 (2002).

8. Hata, K., Okano, M., Lei, H. \& Li, E. Dnmt3L cooperates with the Dnmt3 family of de novo DNA methyltransferases to establish maternal imprints in mice. Development 129, 1983-1993 (2002).

9. Robertson, K. D. DNA methylation and human disease. Nat. Rev. Genet. 6 , 597-610 (2005)

10. Dawson, M. A. \& Kouzarides, T. Cancer epigenetics: from mechanism to therapy. Cell 150, 12-27 (2012).

11. Jones, P. A. \& Baylin, S. B. The fundamental role of epigenetic events in cancer. Nat. Rev. Genet. 3, 415-428 (2002).

12. Hamidi, T., Singh, A. K. \& Chen, T. Genetic alterations of DNA methylation machinery in human diseases. Epigenomics 7, 247-265 (2015).

13. Ley, T. J. et al. DNMT3A mutations in acute myeloid leukemia. N. Engl. J. Med. 363, 2424-2433 (2010).

14. Yamashita, Y. et al. Array-based genomic resequencing of human leukemia Oncogene 29, 3723-3731 (2010).

15. Yang, L., Rau, R. \& Goodell, M. A. DNMT3A in haematological malignancies. Nat. Rev. Cancer 15, 152-165 (2015).

16. Lu, R. et al. Epigenetic perturbations by Arg882-mutated DNMT3A potentiate aberrant stem cell gene-expression program and acute leukemia development. Cancer Cell 30, 92-107 (2016).

17. Russler-Germain, D. A. et al. The R882H DNMT3A mutation associated with AML dominantly inhibits wild-type DNMT3A by blocking its ability to form active tetramers. Cancer Cell 25, 442-454 (2014).

18. Spencer, D. H. et al. CpG island hypermethylation mediated by DNMT3A Is a consequence of AML progression. Cell 168, 801-816 e813 (2017).

19. Kim, S. J. et al. A DNMT3A mutation common in AML exhibits dominantnegative effects in murine ES cells. Blood 122, 4086-4089 (2013).

20. Emperle, M. et al. The DNMT3A R882H mutation does not cause dominant negative effects in purified mixed DNMT3A/R882H complexes. Sci. Rep. 8, 13242 (2018).

21. Emperle, M. et al. The DNMT3A R882H mutant displays altered flanking sequence preferences. Nucleic Acids Res. 46, 3130-3139 (2018).

22. Holz-Schietinger, C., Matje, D. M. \& Reich, N. O. Mutations in DNA methyltransferase (DNMT3A) observed in acute myeloid leukemia patients disrupt processive methylation. J. Biol. Chem. 287, 30941-30951 (2012).

23. Nguyen, T. V. et al. The R882H DNMT3A hotspot mutation stabilizes the formation of large DNMT3A oligomers with low DNA methyltransferase activity. J. Biol. Chem. 294, 16966-16977 (2019).

24. Zhang, Z. M. et al. Structural basis for DNMT3A-mediated de novo DNA methylation. Nature 554, 387-391 (2018).

25. Emperle, M. et al. Mutations of R882 change flanking sequence preferences of the DNA methyltransferase DNMT3A and cellular methylation patterns. Nucleic Acids Res. 47, 11355-11367 (2019).
26. Guo, X. et al. Structural insight into autoinhibition and histone H3-induced activation of DNMT3A. Nature 517, 640-644 (2015).

27. Jia, D., Jurkowska, R. Z., Zhang, X., Jeltsch, A. \& Cheng, X. Structure of Dnmt3a bound to Dnmt3L suggests a model for de novo DNA methylation. Nature 449, 248-251 (2007).

28. Zhou, L. et al. Zebularine: a novel DNA methylation inhibitor that forms a covalent complex with DNA methyltransferases. J. Mol. Biol. 321, 591-599 (2002).

29. Aoki, A. et al. Enzymatic properties of de novo-type mouse DNA (cytosine-5) methyltransferases. Nucleic Acids Res 29, 3506-3512 (2001).

30. Gowher, H.\& Jeltsch, A. Enzymatic properties of recombinant Dnmt3a DNA methyltransferase from mouse:the enzyme modifies DNA in a non-processive manner and also methylates non-CpG[correction of non-CpA] sites. J. Mol. Biol. 309, 1201-1208 (2001)

31. He, Y. \& Ecker, J. R. Non-CG methylation in the human genome. Annu. Rev genomics Hum. Genet. 16, 55-77 (2015)

32. Lister, R. et al. Human DNA methylomes at base resolution show widespread epigenomic differences. Nature 462, 315-322 (2009).

33. Ramsahoye, B. H. et al. Non-CpG methylation is prevalent in embryonic stem cells and may be mediated by DNA methyltransferase 3a. Proc. Natl Acad. Sci. USA 97, 5237-5242 (2000)

34. Kulis, M. \& Esteller, M. DNA methylation and cancer. Adv. Genet. 70, 27-56 (2010).

35. Handa, V. \& Jeltsch, A. Profound flanking sequence preference of Dnmt3a and Dnmt3b mammalian DNA methyltransferases shape the human epigenome. J. Mol. Biol. 348, 1103-1112 (2005).

36. Jurkowska, R. Z., Siddique, A. N., Jurkowski, T. P. \& Jeltsch, A. Approaches to enzyme and substrate design of the murine Dnmt3a DNA methyltransferase. Chembiochem.: Eur. J. Chem. Biol. 12, 1589-1594 (2011).

37. Lin, I. G., Han, L., Taghva, A., O’Brien, L. E. \& Hsieh, C. L. Murine de novo methyltransferase Dnmt3a demonstrates strand asymmetry and site preference in the methylation of DNA in vitro. Mol. Cell Biol. 22, 704-723 (2002).

38. Wienholz, B. L. et al. DNMT3L modulates significant and distinct flanking sequence preference for DNA methylation by DNMT3A and DNMT3B in vivo. PLoS Genet. 6, e1001106 (2010).

39. Hashimoto, H. et al. Recognition and potential mechanisms for replication and erasure of cytosine hydroxymethylation. Nucleic Acids Res. 40, 4841-4849 (2012).

40. Jeltsch, A. On the enzymatic properties of Dnmt1: specificity, processivity, mechanism of linear diffusion and allosteric regulation of the enzyme. Epigenetics 1, 63-66 (2006)

41. Song, J., Rechkoblit, O., Bestor, T. H. \& Patel, D. J. Structure of DNMT1-DNA complex reveals a role for autoinhibition in maintenance DNA methylation. Science 331, 1036-1040 (2011).

42. Song, J., Teplova, M., Ishibe-Murakami, S. \& Patel, D. J. Structure-based mechanistic insights into DNMT1-mediated maintenance DNA methylation. Science 335, 709-712 (2012).

43. Otwinowski, Z. \& Minor, W. Processing of X-ray diffraction data collected in oscillation mode. Method Enzymol. 276, 307-326 (1997)

44. McCoy, A. J. et al. Phaser crystallographic software. J. Appl. Crystallogr. 40, 658-674 (2007).

45. Adams, P. D. et al. PHENIX: building new software for automated crystallographic structure determination. Acta Crystallogr. D: Biol. Crystallogr. 58, 1948-1954 (2002).

46. Emsley, P. \& Cowtan, K. Coot: model-building tools for molecular graphics. Acta Crystallogr. D: Biol. Crystallogr. 60, 2126-2132 (2004).

\section{Acknowledgements}

The authors would like to thank staff members at the Advanced Light Source (ALS), Lawrence Berkeley National Laboratory and Stanford Synchrotron Radiation Light source (SSRL), SLAC National Accelerator Laboratory for access to X-ray beamlines. The Advanced Light Source is supported by the Director, Office of Science, Office of Basic Energy Sciences, of the U.S. Department of Energy under Contract No. DE-AC0205CH11231. Use of the Stanford Synchrotron Radiation Lightsource, SLAC National Accelerator Laboratory, is supported by the U.S. Department of Energy, Office of Science, Office of Basic Energy Sciences under Contract No. DE-AC02-76SF00515. This work was supported by NIH grant 1R35GM119721 (to J.S.).

\section{Author contributions}

H.A. performed protein expression and purification, enzymatic assays, crystallization and structure determination. J.F. assisted the enzymatic assays. J.S. conceived the project and performed structural refinement and analysis. J.S. prepared the manuscript with input from H.A. and J.F.

\section{Competing interests}

The authors declare no competing interests. 


\section{Additional information}

Supplementary information is available for this paper at https://doi.org/10.1038/s41467020-16213-9.

Correspondence and requests for materials should be addressed to J.S.

Peer review information Nature Communications thanks the anonymous reviewer(s) for their contribution to the peer review of this work.

Reprints and permission information is available at http://www.nature.com/reprints

Publisher's note Springer Nature remains neutral with regard to jurisdictional claims in published maps and institutional affiliations. (c) (i) Open Access This article is licensed under a Creative Commons Attribution 4.0 International License, which permits use, sharing, adaptation, distribution and reproduction in any medium or format, as long as you give appropriate credit to the original author(s) and the source, provide a link to the Creative Commons license, and indicate if changes were made. The images or other third party material in this article are included in the article's Creative Commons license, unless indicated otherwise in a credit line to the material. If material is not included in the article's Creative Commons license and your intended use is not permitted by statutory regulation or exceeds the permitted use, you will need to obtain permission directly from the copyright holder. To view a copy of this license, visit http://creativecommons.org/ licenses/by/4.0/.

(C) The Author(s) 2020 